\title{
KONTRIBUSI PARTISIPASI KOMITE TERHADAP MUTU LAYANAN PENDIDIKAN DI MAN SE-KABUPATEN TANAH DATAR
}

\author{
Sudiman \\ Guru MASPadang Ganting, \\ Koresponden: J I. Rotan Guguak Kota Gadang Hilir Padang Gantiang kabupaten Tanah Datar, \\ email : andesra030579@yahoo.co.id, HP. 085274454531
}

\begin{abstract}
Contribution of Participation Committee on the Quality of Services Education in MAN seKabupaten Tanah Datar. The purpose of this research is to know whether the committee participation has contribution to educational service quality in MAN at Tanah Datar Regency. The population of this study is all of teachers of Islamic Senior High School (MAN) that consist of 145 teachers, and sample of this research is 53 teachers by using proportional stratified random sampling. The data are got by using questionairs, those are analized by using Statistical Package for Social Science (SPSS).

The findings of the research is that the committee participation has contribution to the quality of educational services. The number of contribution is 0,206 . It means that if the participation of the committee is increased, the quality of educational services is good, and vice versa. From the research, it can be concluded that the committee has to improve its participation in schools' activities in order to improve the quality of educational services.
\end{abstract}

Kata Kunci: Partisipasi komite, mutu layanan pendidikan

\section{PENDAHULUAN}

Salah satu masalah yang dihadapi Indonesia dalam bidang pendidikan adalah rendahnya mutu pendidikan. Salah satu penyebab rendahnya kualitas pelayanan pendidikan adalah rendahnya tingkat kepercayaan dan kepuasan pelanggan pendidikan (peserta didik dan orang tuanya) terhadap layanan jasa pendidikan. Rendahnya kualitas pelayanan pendidikan pada pelanggan seringkali terjadi disebabkan oleh para pengelola lembaga pendidikan mengabaikan nilai-nilai universal yaitu nilai-nilai Islam (Noor, 2010:4). Kini saatnya lembaga pendidikan khususnya lembaga pendidikan Islam untuk mengkaji kembali nilai-nilai Islam dan mengimplementasikannya dalam meningkatkan kualitas pelayanan kepada para pelanggannya, agar lembaga pendidikan islam tetap jaya dan memiliki daya saing di tengah persaingan global yang semakin ketat.

Menurut Nanang Fatah (2004:25), banyak faktor yang menyebabkan rendahnya mutu pendidikan. Salah satunya diantaranya 
adalah proses pemberian layanan pendidikan yang masih jauh dari harapan. Di satu pihak pemberian layanan pendidikan belum menemukan cara yang paling tepat, dipihak lain pesatnya perkembangan ilmu pengetahuan dan teknologi serta semakin tingginya kehidupan masyarakat telah semakin meningkatnya tuntutan kebutuhan hidup sosial masyarakat sebagai pelanggan pendidikan (Nanang, 2004:28). Semakin tinggi kehidupan sosial masyarakat sejalan dengan perkembangan ilmu pengetahuan dan teknologi telah semakin meningkatkan tuntutan kebutuhan kehidupan sosial masyarakat.

Berdasarkan survei awal yang dilakukan oleh peneliti pada tanggal 15 September 2012 terhadap beberapa orang guru di MAN 3 Batusangkar yang terletak di Batu Bulat Kecamatan Lintau Buo Utara Kabupaten Tanah Datar bahwa mutu layanan pendidikan masih rendah. Hal ini terlihat dengan seringnya guru melontarkan kata-kata yang tidak baik kepada siswa ketika mereka berurusan dengan guru, baik di kantor maupun di dalam kelas, sehingga menyebabkan turunnya motivasi siswa dalam belajar. Jika hal ini dibiarkan secara terus menerus, maka akan mengakibatkan rendahnya minat belajar siswa, sehingga akan berdampak pada rendahnya mutu lulusan.

Mutu layanan pendidikan sekurangkurangnya ditentukan oleh beberapa faktor, yaitu faktor sarana dan prasarana, media pembelajaran, guru, motivasi siswa, supervisi, partisipasi komite madrasah dan kebijakan kepala madrasah. Dalam bidang sarana dan prasarana, belum adanya laboratorium yang memadai dan alat/ bahan praktek sangat minim. Belajar mata pelajaran Teknologi Informasi Komputer (TIK) dengan komputer yang masih terbatas (1 komputer 2 orang siswa), serta buku pegangan peserta didik masih banyak yang kurang. Selain itu, peralatan berupa alat peraga, alat/bahan praktek, media pembelajaran dan alat-alat pembelajaran lainnya dikebanyakan madrasah masih sangat terbatas.

Berdasarkan permasalahanpermasalahan tersebut di atas, maka penulis melakukan penelitian dengan judul "Kontribusi Partisipasi Komite terhadap Mutu Layanan Pendidikan di Madrasah Aliyah Negeri Se Kabupaten Tanah Datar".

Penelitian ini menggunakan pendekatan kuantitatif korelasional. Adapun alasan Pemilihan metode ini karena penelitian ini bertujuan untuk mengetahui hubungan antara satu variabel dengan variabel lainnya. Melalui metode penelitian kuantitatif deskriptif diharapkan akan mampu mengungkapkan jawaban masalah penelitian yang telah ditetapkan yakni besarnya kontribusi variabel bebas terhadap variabel terikat. Penelitian ini terdiri dari variabel bebas yaitu variabel Partisipasi Komite (X), dihubungkan dengan variabel terikat yaitu Mutu Layanan Pendidikan (Y). Penelitian 
ini dilaksanakan di Madrasah Aliyah Negeri (MAN) Se Kabupaten Tanah Datar, dimulai pada tanggal 21 Desember 2012 sampai dengan tanggal 21 Januari 2013.

Populasi adalah seluruh guru Madrasah Aliyah Negeri (MAN) Se Kabupaten Tanah Datar yang sudah berstatus sebagai Pegawai Negeri Sipil (PNS). Jumlah populasi sebanyak 145 orang yang tersebar pada 4 unit kerja, yaitu MAN 1, MAN 2, Man 3 dan MAN Sumpur. Sedangkan jumlah sampel dalam penelitian sebanyak 53 orang yang diperoleh dengan menggunakan teknik Proportional Stratified Random Sampling. Instrumen yang digunakan untuk mengumpulkan data adalah angket model skala Likert. Menurut Arikunto (2003:33), Skala Likert berisi alternatif respon dalam bentuk kontinum yang terdiri dari lima skala, yaitu Selalu (SL), Sering (SR), Kadang-kadang (KD), Jarang (JR), dan Tidak Pernah (TP). Pernyataan yang bersifat positif diberi skor $S=5, S R=4$, $\mathrm{KD}=3, \mathrm{JR}=4$, dab $\mathrm{TP}=1$, dan pernyataan negatif diberi skor $S=1, S R=2, K D=3$, $\mathrm{JR}=4$, dan $\mathrm{TP}=5$.

Instrumen yang digunakan untuk mengetahui kontribusi partisipasi komite terhadap mutu layanan pendidikan di MAN Se Kabupaten Tanah Datar adalah berupa angket yang terdiri dari beberapa indikator, yaitu pemberi pertimbangan (advisory agency), pendukung (supporting agency), pengontrol (controlling agency) dan mediator (mediating agency). Sedangkan indikator mutu layanan pendidikan meliputi: keandalan (reliability), daya tanggap (responsiveness), kepastian (assurance),empati (emphaty) dan berwujud (tangible).

Rangkuman hasil analisis reliabilitas instrumen terdapat pada tabel berikut:

Tabel 1

Rangkuman hasil analisis reliabilitas instrumen

\begin{tabular}{|l|l|l|l|l|}
\hline \multirow{2}{*}{\multicolumn{1}{|c|}{ Variabel }} & \multirow{2}{*}{$\mathbf{R}_{\text {hitung }}$} & \multicolumn{2}{|c|}{$\mathbf{R}_{\text {tabel }}$} & \multirow{2}{*}{ Keterangan } \\
\cline { 3 - 4 } & & $\alpha=\mathbf{0 , 0 5}$ & $\alpha=\mathbf{0 , 0 1}$ & \\
\hline Partisipasi Komite & 0,933 & 0,374 & 0,463 & Handal \\
\hline Mutu Layanan Pendidikan & 0,951 & 0,374 & 0,463 & Handal \\
\hline
\end{tabular}

\section{PEMBAHASAN}

Penelitian ini mendeskripsikan variabel penelitian, yaitu variabel partisipasi komite (X) dan variabel mutu layanan pendidikan (Y). Dalam rangka memeperoleh data yang akurat, maka dalam penelitian ini digunakan angket yang sudah diisi secara akurat oleh 53 orang responden. Hasil statistik data kedua varaibel tersebut seperti terlihat pada Tabel 5 di bawah ini:

Tabel 2

Perhitungan Statistik Data Penelitian

\begin{tabular}{|l|l|l|}
\hline \multicolumn{1}{|c|}{ Statistik } & \multicolumn{1}{|c|}{$\begin{array}{c}\text { Mutu Layanan } \\
\text { Pendidikan (Y) }\end{array}$} & \multicolumn{1}{|c|}{$\begin{array}{c}\text { Partisipasi } \\
\text { Komite (X) }\end{array}$} \\
\hline $\mathrm{N}$ & 53 & 53 \\
\hline Rata-Rata (Mean) & 182.9623 & 138.9434 \\
\hline Skor tengah (median) & 180.0000 & 136.0000 \\
\hline Skor yang banyak muncul (mode) & 184.00 & 137.00 \\
\hline Simpangan baku & 15.67330 & 10.06597 \\
\hline Skor terendah & 138.00 & 120.00 \\
\hline Skor tertinggi & 215.00 & 157.00 \\
\hline
\end{tabular}

Berdasarkan butir instrumen yang berjumlah sebanyak 43 butir, maka skor ideal minimal yang dapat dicapai adalah 43 dan skor maksimal 215. Data yang diperoleh dari jawaban responden bahwa skor terendah adalah 138 dan tertinggi adalah 215. Skor 
rata-rata (mean) sebesar 182.9623, nilai tengah (median) sebesar 180,000, modus (mode) sebesar 184, dan simpangan baku (standard deviation) sebesar 18,03645. Hasil perhitungan tersebut menunjukkan bahwa selisih skor rata-rata, median dan modus tidak melebihi satu simpangan baku. Ini berarti bahwa distribusi frekuensi data mutu layanan pendidikan cendrung normal.

Sedangkan butir-butir pernyataan variabel Partisipasi komite yang berjumlah 33 butir, maka skor minimal (minimum) yang mungkin diperoleh adalah 33 dan skor maksimal (maximum) adalah 165. Kenyataan dari data yang diperoleh skor terendah (minimum) adalah 120 dan yang tertinggi (maximum) adalah 157. Skor rata-rata (mean) sebesar 138.9434, nilai tengah (median) sebesar 136.000, modus (mode) sebesar 137, dan simpangan baku (standard deviation) sebesar 10.06597. Hasil perhitungan tersebut menunjukkan bahwa selisih skor rata-rata, median dan modus tidak melebihi satu simpangan baku. Ini berarti bahwa distribusi frekuensi data partisipasi komite cendrung normal.

Berdasarkan hasil analisis data dan tingkat pencapaian responden setiap variabel ukur dapat diterangkan tingkat pencapaian masing-masing variabel yang ada dalam penelitian ini. Tingkat pencapaian partisipasi komite (X) berada pada kategori baik. Partisipasi komite mempunyai hubungan yang signifikan dengan mutu layanan pendidikan. Dari skor jawaban pada variabel partisipasi komite termasuk pada kategori baik (84\%) dari skor ideal. Berdasarkan hasil penelitian ini, mutu layanan pendidikan di Madrasah Aliyah Negeri (MAN) yang ada di Kabupaten Tanah Datar termasuk dalam kategori baik yaitu $85 \%$ dari skor ideal. Rangkuman tingkat pencapaian responden dapat dlihat pada Tabel 6 di bawah ini:

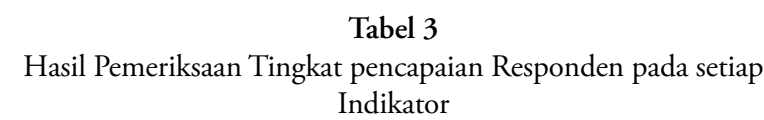

\begin{tabular}{|c|c|c|c|c|c|}
\hline No & Variabel & Indikator & $\begin{array}{c}\text { Rata- } \\
\text { rata }\end{array}$ & $\begin{array}{c}\text { Tingkat } \\
\text { pencapaian }\end{array}$ & $\begin{array}{c}\text { Kategori } \\
\text { pencapaian }\end{array}$ \\
\hline (1) & $(2)$ & (3) & $(4)$ & (5) & (6) \\
\hline \multirow[t]{4}{*}{1} & \multirow[t]{4}{*}{$\begin{array}{l}\text { Partisipasi } \\
\text { Komite } \\
\text { (X1) }\end{array}$} & $\begin{array}{l}\text { 1.pemberi } \\
\text { pertimbangan } \\
\text { (advisory agency) }\end{array}$ & 228,75 & 86,32 & $\begin{array}{l}\text { Sangat } \\
\text { Baik }\end{array}$ \\
\hline & & \begin{tabular}{|l} 
2.pendukung \\
(supporting agency)
\end{tabular} & 227,38 & 85,80 & Baik \\
\hline & & $\begin{array}{l}\text { 3.pengontrol } \\
\text { (controlling agency) }\end{array}$ & 218 & 82,26 & Baik \\
\hline & & $\begin{array}{l}\text { 4. mediator (mediating } \\
\text { agency) }\end{array}$ & 219,13 & 82,69 & Baik \\
\hline \multirow[t]{5}{*}{2} & \multirow{5}{*}{$\begin{array}{l}\text { Mutu } \\
\text { Layanan } \\
\text { Pendidikan } \\
(\mathrm{Y})\end{array}$} & $\begin{array}{r}\text { 1. Keandalan } \\
\text { (reliability) }\end{array}$ & 229,50 & 86,60 & $\begin{array}{l}\text { Sangat } \\
\text { Baik }\end{array}$ \\
\hline & & \begin{tabular}{|l}
$\begin{array}{l}\text { 2. Daya tanggap } \\
\text { (responsiveness) }\end{array}$ \\
\end{tabular} & 215,8 & 81,42 & Baik \\
\hline & & 3. Kepastian (assurance) & 228,38 & 86,04 & $\begin{array}{l}\text { Sangat } \\
\text { Baik }\end{array}$ \\
\hline & & 4. Empati (emphaty) & 221,30 & 83,51 & Baik \\
\hline & & 5. Berwujud (tangible) & 222,10 & 83,81 & Baik \\
\hline
\end{tabular}

Dari Tabel di atas, dapat kita kemukakan beberapa temuan sebagai berikut: Pertama, Pada variabel partisipasi komite $(\mathrm{X})$ taraf pencapaian responden untuk semua indikator mempunyai rata-rata baik. Hal ini mengambarkan bahwa partisipasi komite pada Madrasah Aliyah Negeri (MAN) se Kabupaten Tanah Datar sudah baik. Kedua, pada variabel mutu layanan pendidikan, taraf pencapaian responden pada indikator yang disediakan juga baik. Berarti kedua variabel penelitian mempunyai tingkat capaian responden yang baik. 
Dari data hasil analisis yang telah dijelaskan pada bagian terdahulu bahwa variabel bebas mempunyai hubungan secara signifikan dan positif dengan variabel terikat. Hasil analisis data dan pengujian hipotesis menunjukkan bahwa hipotesis yang diuji dalam penelitian ini diterima secara empiris. Dengan demikian, dapat diyakini bahwa variabel partisipasi komite $(\mathrm{X})$ memberikan kontribusi yang berarti dan signifikan terhadap mutu layanan pendidikan (Y) pada Madrasah Aliyah Negeri (MAN) se Kabupaten Tanah.

Hasil analisis tersebut juga menunjukkan bahwa variabel partisipasi komite memberikan kontribusi yang berarti dan signifikan terhadap variabel mutu layanan pendidikan pada Madrasah Aliyah Negeri (MAN) se Kabupaten Tanah Datar. Hal ini menguatkan dugaan awal penulis bahwa partisipasi komite mempunyai hubungan dengan mutu layanan pendidikan di Madrasah Aliyah Negeri (MAN) se Kabupaten Tanah Datar. Ini berarti bahwa komite madrasah perlu meningkatkan perannya di madrasah dalam rangka meningkatkan mutu layanan pendidkan di Madrasah Aliyah Negeri (MAN) se Kabupaten Tanah Datar. Jika komite berpartisipasi secara aktif dalam setiap kegiatan di Madrasah, maka akan membawa dampak terhadap peningkatan mutu layanan pendidikan di Madrasah Aliyah Negeri (MAN) se Kabupaten Tanah Datar.
Menurut Ikke Sartika, bahwa salah satu penyebab rendahnya mutu pendidikan di Indonesia adalah kurangnya perhatian dari stakeholder terhadap pendidikan, salah satu diataranya adalah komite sekolah (madrasah). ${ }^{1}$ Dengan demikian jelaslah bahwa keterlibatan komite dalam setiap kebijakan yang dibuat oleh madrasah dalam rangka meningkat mutu layanan pendidikan sangatlah diperlukan. Oleh karena itu komite madrasah harus lebih meningkatkan perannya di madrasah agar kualitas pendidikan bisa meningkat.

Kebijakan kepala madrasah juga mempunyai hubungan yang signifikan dengan mutu layanan pendidikan. Oleh karena itu kebijakan kepala madrasah juga perlu ditingkatkan lagi agar mutu layanan pendidikan di Madrasah Aliyah Negeri (MAN) se Kabupaten Tanah Datar meningkat. Karena keberhasilan pendidikan juga erat hubungannya dengan kebijakan yang dibuat oleh kepala madrasah. Jika kepala membuat kebijakan yang berpihak kepada kepentingan madrasah, maka mutu pendidikan bisa meningkat.

Hal tersebut sejalan dengan apa yang dikemukan oleh Hafidz, bahwa untuk membangun pendidikan yang bermutu, yang paling penting bukan membangun gedung sekolah atau sarana dan prasarananya, melainkan harus dengan upaya peningkatan proses pengajaran dan pembelajaran yang berkualitas, yakni proses pembelajaran

1. Dewi Sartika, Quality Service In Education, 2002, h. 27 
yang menyenangkan, mengasyikkan dan mencerdaskan. ${ }^{2}$ Kesemuanya itu hanya dapat dilakukan oleh guru yang bermutu. Ini tidak akan bisa tercapai tanpa adanya kebijakan yang dibuat oleh kepala madrasah yang berpihak kepada guru, siswa dan semua warga sekolah.

Selanjutnya jika dilihat tingkat pencapaian variabel partisipasi komite berada pada kategori baik, dengan tingkat pencapaian responden sebesar $84,27 \%$ dari skor ideal. Sementara dari pengujian hipotesis pertama menunjukkan bahwa variabel partisipasi komite memberikan kontribusi yang signifikan terhadap variabel mutu layanan pendidikan pada Madrasah Aliyah Negeri (MAN) se Kabupaten Tanah Datar. Hal ini berarti bahwa partisipasi komite mempunyai hubungan yang prediktif dengan mutu layanan pendidikan di Madrasah Aliyah Negeri (MAN) se Kabupaten Tanah Datar, dengan koefisien korelasi 0,454 dan koefisien determinasi 0,206. Ini menunjukkan bahwa partisipasi komite mempunyai andil dalam meningkatkan mutu layanan pendidikan Madrasah Aliyah Negeri (MAN) di Kabupaten Tanah Datar sebesar 20,6\%. Atinya semakin besar tingkat partisipasi komite dalam kegiatan madrasah, maka akan semakin meningkat pula mutu layanan pendidikan pada Madrasah Aliyah Negeri (MAN) di kabupaten Tanah Datar. Sebaliknya, jika komite tidak ikut serta atau berpartisipasi dalam kegiatan madrasah,

2. Hafidh, Mudzakkir, Analisis Kebijakan Pendidikan. Online. diakses tanggal 24 Januari 2013

lo0 Jurnal al-Fikrah, Vol. I, №. 2, Juli-Desember 2013 maka akan berdampak negatif terhadap mutu layanan pendidikan Madrasah Aliyah Negeri (MAN) di kabupaten Tanah Datar.

Komite sekolah (madrasah) memiliki peran yang sangat strategis dalam rangka ikut berperan meningkatkan kualitas mutu pendidikan di satuan pendidikan. Keberadaan Komite Sekolah itu sendiri berdasarkan berbagai aturan yang saling berhubungan, yaitu Keputusan Mendiknas No.044/U/2002 tertanggal 2 April 2002 tentang Dewan Pendidikan dan Komite Sekolah. Oleh karena itu, komite sekolah/ madrasah harus mampu menjadi lembaga mandiri, dibentuk dan berperan dalam meningkatkan mutu pelayanan dengan memberikan pertimbangan, arahan dan dukungan tenaga, sarana prasarana, serta pengawasan pendidikan pada tingkat satuan pendidikan, terutama di Madrasah Aliyah Negeri (MAN) yang ada di Kabupaten Tanah Datar. Dengan demikian Komite Sekolah (madrasah) dalam rangka memberikan peran tersebut harus mampu meningkatkan peran dan partisipasi aktif stakeholders.

Melalui komite madrasah, orang tua siswa dan masyarakat diharapkan peduli terhadap mutu pendidikan melalui beberapa peran yang diwujudkan dalam aktivitasaktivitas untuk membantu peningkatan mutu pendidikan di sekolah. Dengan kata lain, komite madrasah diharapkan lebih fokus terhadap peningkatan mutu pendidikan. Dengan demikian, keberadaan komite madrasah sangat erat kaitannya 
dengan peningkatan mutu pendidikan di madrasah.

Variabel mutu layanan pendidikan pada Madrasah Aliyah Negeri (MAN) se Kabupaten Tanah Datar memiliki tingkat capaian responden $84,79 \%$. Hal ini menunjukkan bahwa mutu layanan pendidikan pada Madrasah Aliyah Negeri (MAN) se Kabupaten Tanah Datar berada pada kategori baik. Hal ini merupakan faktor yang juga ikut mempengaruhi peningkatan berbagai aspek yang ada di madrasah, seperti guru, siswa, sarana dan prasarana, keuangan dan lain-lain.

Dengan demikian, dalam konteks opeasionalnya peran komite madrasah dalam peningkatan mutu pendidikan tidak hanya terbatas dalam penyusunan anggaran dan dana madrasah saja, tetapi juga terlibat aktif dalam penyusunan berbagai kebijakan dan program sekolah, khususnya tentang perencanan jangka pendek, menengah dan jangka panjang. Komite madrasah diharapkan berperan aktif dalam penyusunan visi, misi, tujuan, dan berbagai program operasional madrasah. Selain itu, komite madrasah juga ikut terlibat dalam evaluasi dan pengawasan pelaksanaan program madrasah.

Pada dasarnya peran dan fungsi dewan pendidikan dan komite madrasah adalah untuk meningkatkan mutu pendidikan di wilayahnya masing-masing, sehingga apabila komite madrasah melaksanakan peran dan fungsinya dengan baik diharapkan akan mampu meningkatkan kinerja pengelolaan pendidikan, dimana kebutuhan untuk proses pembelajaran akan terpenuhi, sehingga siswa dapat menikmati proses pembelajaran yang menyenangkan yang bermuara pada peningkatan mutu pendidikan pada umumnya.

Peningkatan mutu layanan pendidikan di Madrasah Aliyah Negeri (MAN) se Kabupaten Tanah Datar pada masa yang akan datang tentunya diharapkan berubah kearah yang lebih baik lagi. Peningkatan mutu layanan pendidikan ini merupakan hal yang sangat penting dalam rangka menghasilkan output (peserta didik) yang berkualitas dan mampu bersaing dalam berbagai aspek kehidupan. Tapi jika mutu layanan pendidikan kurang baik, maka akan berakibat buruk terhadap mutu pendidikan, tidak hanya di Madrasah Aliyah Negeri di Kabupaten Tanah Datar, tetapi juga untuk lembaga pendidikan yang ada di Indonesia.

Penelitian ini telah dilakukan sesuai dengan prosedur penelitian kuantitatif dalam rangka mendapatkan data dan informasi yang valid dan teruji secara empiris. Namun demikian, penelitian ini tentunya masih mempunyai keterbatasan, diantaranya: (1) karena alat ukur yang digunakan dalam penelitian ini adalah angket, maka tidak tertutup kemungkinan ada responden yang memberikan jawaban secara tidak objektif atau tidak sesuai dengan keadaan yang sebenarnya. (2) karena yang diteliti dalam penelitian ini hanya dua 
variabel, sedangkan yang mempengaruhi mutu layanan pendidikan tidak hanya satu variabel bebas di atas, masih banyak variabel bebas lain yang berhubungan dengan variabel mutu layanan pendidikan yang tidak disebutkan dalam penelitian ini. Oleh karena itu peneliti menyadari dengan sesungguhnya kelemahan-kelemahan atau kekurangan-kekurangan yang ada dalam penelitian ini.

\section{PENUTUP}

Berdasarkan hasil analisis deskriptif dan uji hipotesis sebagaimana yang telah dikemukakan di atas, dapat diambil kesimpulan bahwa terdapat kontribusi partisipasi komite terhadap mutu layanan pendidikan sebesar 0,206 atau 20,6\%. Sifat korelasi positif menunjukkan bahwa semakin besar partisipasi komite semakin meningkat mutu layanan pendidikan, dan sebaliknya. Nilai signifikan $r_{\text {hitung }}$ sebesar 0,001 berarti hubungan tersebut signifikan atau diterima pada taraf $\alpha=0,05 \%$. Bila ingin meningkatkan mutu layanan pendidikan di madrasah, maka hal yang perlu dilakukan adalah meningkatkan peran komite madrasah dalam setiap kegiatan yang diadakan oleh madrasah. Karena bila partisipasi komite meningkat, maka mutu layanan pendidikan di madrasah juga akan meningkat.

Temuan ini mengimplikasikan bahwa partisipasi komite perlu ditingkatkan kearah yang lebih baik, sehingga komite madrasah mampu menjadi pemberi pertimbangan, sebagai pendukung, sebagai pengontrol dan sebagai mediator bagi madrasah. Dengan keterlibatan komite dalam setiap kegiatan yang diadakan oleh madrasah, maka peran komite madrasah akan semakin meningkat. Peran komite yang selama ini dianggap hanya sebagai pemberi legalitas akan berubah menjadi komite yang betul-betul punya arti dan punya peran bagi madrasah.

Berdasarkan kesimpulan di atas, maka disarankan kepada komite madrasah agar selalu berperan aktif sebagai pemberi pertimbangan, pendukung, pengawas dan mediator bagi madrasah, sehingga seluruh aktivitas elemen-elemen yang terdapat di madrasah dapat menjalankan program sesuai dengan ketentuan yang telah ditetapkan. Partisipasi ini perlu dikelola dan dikoordinasikan dengan baik agar lebih bermakna bagi madrasah, terutama dalam peningkatan mutu dan efektifitas pendidikan lewat suatu wadah, yaitu Dewan Pendidikan di tingkat Kabupaten/Kota dan Komite madrasah di setiap satuan pendidikan.

\section{KEPUSTAKAAN ACUAN}

Ali Imron, Kebijkasanaan Pendidikan di Indonesia Proses, Produk dan Masa Depannya (Jakarta: Bumi Aksara, 2008. Arikunto, Suharsimi. Prosedur Penelitian. Jakarta: PT Aneka Cipta, 2000.

Depdiknas, Undang-Undang Otonomi Daerah 1999 dan Petunjuk Pelaksanaan 
Undang-Undang Otonomi Daerah. dalam Rangka Peningkatan Mutu dan Penerbit CV. Restu Agung Jakarta, 2003. Kemandirian Sekolah. Bandung : CV

Depdiknas, Manajemen Mutu Berbasis Andira, 2000.

Madrasah . Jakarta: Dirjen Dikdasmen, Siahaan. School Based Management. Ciputat 2004.

: Quantum Teaching, 2006.

Mulyasa, E, Manajemen Berbasis Madrasah. Sudjana, Teknik Analisis Regresi dan Korelasi Bandung: Rosda, 2003.

Nanang Fattah, Manajemen Berbasis bagi Para Peneliti. Bandung: Tarsito, 1992.

Sekolah: Strategi Pemberdayaan Sekolah 